ESCENA

Revista de las artes
Publicación semestral. ISSN 2215-4906

Volumen 78 - Número 2

Enero - Junio 2019

\title{
Marisol Gutiérrez Rojas. \\ Del semillero de sueños a la cosecha de recuerdos. 40 aniversario del taller nacional de teatro
}

\author{
Madelaine Martínez Rojas
}

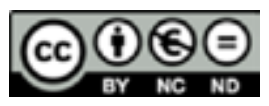

Esta obra está bajo una licencia Creative Commons Reconocimiento-No comercial-Sin Obra Derivada 
Reseñas

\title{
Marisol Gutiérrez Rojas, Del semillero de sueños a la cosecha de recuerdos. 40 aniversario del Taller Nacional de Teatro
}

\author{
Madelaine Martínez Rojas' \\ Universidad de Costa Rica \\ Costa Rica
}

Recibido: 16 de mayo del 2018 Aprobado: 29 de agosto del 2018

Hace algunos años, cuando mi amiga, compañera y colega Marisol Gutiérrez me comentó su idea de hacer un recuento sobre los años de existencia del Taller Nacional de Teatro (TNT) me pareció importante e interesante; una necesidad vital en la historia del movimiento teatral costarricense. ¡Cuarenta años de labor ininterrumpida! No deja de ser una labor titánica recopilar y analizar el dinámico y trascendente trabajo del TNT. Marisol nos facilita, primero que nada, el panorama político y cultural en el que se da el nacimiento del TNT: la década de 1970. Señala tres acontecimientos de gran relevancia sucedidos en el ámbito cultural costarricense, en general, que mantienen un vínculo significativo con la escena teatral costarricense; en específico: la creación del Ministerio de Cultura Juventud y Deportes (MCJD); la llegada al país de diversas personalidades que se insertan en el ámbito laboral y docente-teatral, y el creciente interés de la población no solo por ver teatro, sino por formarse profesionalmente.

En su investigación, Gutiérrez nos conduce a través de esos cuarenta años de creación, desarrollo y consolidación del TNT, al exponer y analizar acciones fundamentales, tanto individuales como institucionales, que resultaron trascendentes para la formación académica y no académica de los profesionales del teatro, instituciones de enseñanza formal y no formal. Al revisar el decreto de fundación del TNT de 1977, así como sus modificaciones de 1994 y 1999, se vislumbran las políticas culturales puestas en marcha por los diversos gobiernos de turno y su incidencia real en la conformación de nuestro actual estado del teatro.

1 Profesora interina de la Escuela de Artes Dramáticas de la Universidad de Costa Rica (UCR). Licenciada en Artes Dramáticas por la UCR. Egresada del Taller Nacional de Teatro, generación de 1997. Correo electrónico madelaine.martinez@ucr.ac.cr 
Gutiérrez también señala algunos de los logros y obstáculos que la institución ha vivido: intentos repetidos de cerrar el TNT; consensos y disensos en el espacio formativo entre las escuelas de teatro universitarias y el TNT; logros importantísimos, como el convenio con el Ministerio de Educación Pública (MEP) para la capacitación de maestros y el Teatro Aplicado a la Educación; la dificultad de trabajar con un presupuesto escaso; el proyecto de desarrollar "sedes" del TNT en las provincias y de "exportar" el proyecto TNT a otros países centroamericanos, entre otros. Luego, el libro se adentra en una (para mí) deliciosa y muy amena conversación con sus directores (los presentes y el gran ausente). Al llegar a esta parte, fue inevitable la cascada de imágenes, recuerdos, sentimientos, emociones que se desbordaron de mi mente y de mi corazón. Confieso que no me he podido mantener al margen y preservar mi objetividad ante el material, como habría sido mi deseo desde la óptica de la academia. He tenido que vencer una dura lucha emocional, para cumplir con el objetivo de hacer la reseña, he llegado a la conclusión de que la forma más honesta de abordarlo es desde mi propia experiencia como egresada del TNT.

Empezaré por contar que Marisol y yo fuimos compañeras en el TNT, en la generación de 1979. Tuvimos la gran oportunidad de que nuestro cuerpo docente estuviera conformado por don Oscar Fessler, Gladys Catania, Luis Fernando Gómez, Eugenia Chaverri, Rodolfo Araya (padre), Diego Díaz y Lianne Solís, todos ellos protagonistas del nacimiento y posterior desarrollo del TNT. Compartí mi estadía formativa con diversos profesionales del teatro como Rolando Martén, Francisco (Chico) Campos, Rubén Garro, Magda Araya, Víctor Valdelomar, Lorena Delgado y mis queridos compañeros de clase Cinthya Crespo, Osvaldo Carranza, Ana Carvajal, Marcela Musso, Nancy Piedra, Jimmy Ortiz y muchos otros de mi generación y de otras generaciones; así como amigos y admiradores del TNT. En el campo profesional, es muy frecuente reencontrarnos con los alumnos del Taller. Trabajamos como colegas en montajes, dando clases, en proyectos de diversa naturaleza, como jurados y tantas otras actividades; me atrevería a decir, sin miedo a equivocarme, que tenemos una "marca", algo que nos identifica a todas las generaciones: "la convicción de Fessler por el valor del trabajo en equipo, la exploración de las capacidades creadoras individuales y la finalidad del teatro" (Gutiérrez, 2018, p. 25).

\section{Don Oscar Fessler}

Hablar de don Oscar es, por así decir, como hablar de nuestro "padre en el teatro". Varios de nuestra generación llegábamos a las clases con el uniforme del colegio. Muy jóvenes quizás, pero con una vocación muy definida. Como bien lo menciona Gutiérrez, don Oscar aporta, con su formación, gran experiencia teatral y pedagógica a la fundación del TNT. Él poseía una extraordinaria sensibilidad para comprender y guiar a quienes acudían llenos de ilusión y esperanza por realizar su sueño como artistas. Persona rigurosa y muy 
observadora, abordaba el trabajo de cada estudiante desde su visión humanista, procuraba guiar el desarrollo de las habilidades y destrezas de cada estudiante, siempre con respeto y lograba sembrar la curiosidad, la observación del entorno y la fascinación por el juego.

\section{Los Catania}

Alfredo, Gladys y Carlos fueron, y seguirán siendo, para las generaciones del TNT y otras generaciones fuera de la institución, un referente fuerte, preciso y metodológico. Gladys luchó por desarrollar la infraestructura del TNT, por mejorar las condiciones de las clases. También buscó, cada vez más, un lenguaje lo más cercano a los estudiantes. Por su parte, Carlos fue profesor de dramaturgia, de su mano muchos estudiantes se enfrentaron al reto de escribir y crearon sus primeras piezas teatrales. Su hermano Alfredo, creador y director del Teatro Carpa, llevó el teatro a los últimos rincones de Costa Rica y, entre otras tareas, fue director de la Compañía Nacional de Teatro. Sin duda los Catania aportaron en gran medida a la profesionalización del teatro en Costa Rica.

\section{Don Guido Sáenz}

Un hombre integral en el arte, visionario y férreo luchador, apoyó la creación de los centros civiles, de las giras al interior y exterior de país. Fue defensor del espacio que ocupa hoy el Teatro de la Aduana-Compañía Nacional de Teatro, de la Lírica Nacional, de la Sinfónica Nacional y fundador de museos. Sin el amor de don Guido por el arte y su pasional defensa, quizás muchas de estas instituciones nunca hubieran existido o ya habrían desaparecido.

\section{Los profesores}

Los profesores del Taller lograron heredar, a su vez, el espíritu de don Oscar. En el quehacer cotidiano del teatro, en la Gran Área Metropolitana, o fuera de ella, en los diferentes espacios de creación a los que se enfrentan los profesionales, el TNT permite sentido de pertenencia y visión de futuro. Gracias al arduo trabajo de los profesores se ha logrado consolidar, no solo una visión de "hacer" teatro, sino un "lenguaje" común, una metodología, un bagaje propio. Pero, sobre todo, hay una vocación claramente definida y una necesidad imperante, de hacer teatro y, además, de investigar, de retarse en la cotidianidad, en la construcción y exploración de nuevas herramientas pedagógicas, sin por ello descartar la ya establecidas. 


\section{Los directores}

El primer director del Taller Nacional de Teatro, don Oscar Fessler marcó, de forma indeleble, lo que significa asumir una institución con estas características e independientemente de los vientos que soplarán, no flaquear nunca en los principios formativos de sus alumnos. Ese camino - con esa rigurosidad, ese desafío y esa innovación constante- ha sido transitado por los diferentes directores del TNT, con una gran ventaja: en su mayoría, también fueron profesores o alumnos del Taller y, luego, dirigieron la institución, quienes conocen el TNT desde sus cimientos. Ellos han acompañado desde diferentes instancias el devenir de la institución; han compartido con casi todos sus egresados y se han ocupado y preocupado por aglutinar a esta enorme descendencia bajo múltiples actividades, producciones, puestas en escena, proyectos diversos, con el imperativo de que el TNT continúe su labor y de darle a los egresados, talleristas y otros, el sentido de pertenencia, vital para nuestro quehacer y para el ser humano.

\section{Los egresados}

Gutiérrez constata y aporta en los anexos cómo los egresados del TNT se han insertado laboralmente en muchos y variados espacios de creación artística en el medio profesional costarricense y en el extranjero. Incluso destaca, también, cómo han ingresado a la academia universitaria y se han seguido preparando constantemente; conscientes de que la mujer y el hombre de teatro permanecen en formación continua hasta el final, recordándonos, así, otra máxima del oficio teatral.

\section{Centros cívicos}

El espíritu inquebrantable del TNT se ha esforzado por llevar el teatro en todas sus formas, a todos los espacios posibles: asociaciones, comunidades, instituciones, zonas urbano-marginales, zonas rurales, colegios y escuelas de casi todo el país. En los últimos años, ha estado, también, al servicio de los Centros Cívicos para la Paz, tarea con la cual, fortalece el derecho a la cultura, la prevención de la violencia y la inclusión social. Este recorrido por los cuarenta años del Taller Nacional de Teatro nos hace pensar que, en una sociedad, en constante transformación, como la costarricense, sometida a retos cada vez más exigentes en lo político, lo económico y lo cultural, una institución como el TNT tiene que prevalecer y contar con un presupuesto acorde con su visión y misión, así como con una infraestructura adecuada para los propósitos formativos que persigue. Con 40 años de labor ininterrumpida y 500 egresados el TNT es, sin duda, una institución que ha bregado para cumplir sus objetivos. 
El arte, como ya se ha dicho, no solo reditúa económicamente, sino que "salva" vidas, da herramientas para conocerse a sí mismo, para transformar al ser humano y, con ello, cambiar su entorno. Entonces, ¿cuál es la respuesta ante el futuro? Es necesario un mayor acompañamiento entre las instituciones adscritas del MCJ para lograr un trabajo realmente colaborativo, este es un principio que el TNT enseña a sus estudiantes. Debería ser, también, un principio regente en los planes de trabajo en torno a la cultura. El aporte del Estado es necesario y obligatorio, para desarrollar y concretar cada vez más iniciativas vitales referentes a la cultura y el arte. Este trabajo continuo y los logros alcanzados a lo largo de sus 40 años de existencia, deberían ser suficiente para que el presupuesto del TNT sea fortalecido, para asegurar una estabilidad que le permita seguir creciendo y acceder a otros espacios que, hasta ahora, no le ha sido posible. Un ambiente nuevo, propicia nuevos

horizontes y nuevos objetivos. Sirva este libro para sopesar estas consideraciones.

\section{Referencia:}

Gutiérrez Rojas, M. (2018). Del semillero de sueños a la cosecha de recuerdos. San José, Costa Rica: Micro-Print S.A. 